\title{
Interpolation formulas for Balling's alcohol factors
}

\author{
Jan Šavel ${ }^{1 *}$, Petr Košin ${ }^{1}$, Adam Brož $^{1}$, Jakub Vlček ${ }^{1}$ \\ 1 Budějovický Budvar, n.p., Karolíny Světlé 4, \\ 37021 České Budějovice, Czech Republic
}

* coresponding author: jan.savel@budvar.cz

\begin{abstract}
The article deals with the interpolation of the Balling alcohol factors, given at isolated points in $1 \%(\mathrm{~m} / \mathrm{m})$ increments ranging from 1 to $30 \%$ in the Hrach table published in 1927. Interpolation was necessery for the calculation of real (RDF) or apparent (ADF) degree of attenuation, according to which optimal barley varieties were selected for beer production. Analytica EBC initially preferred ADF, although it also reported on the RDF used by ASBC. According to ASBC, the Balling RDF is multiplied by a correction factor or calculated using a modified calculation formula. Both ways gave the same results and increased Balling RDF values by $1-2 \% \mathrm{~m} / \mathrm{m}$. Refractometry with a pocket digital refractometer set to ${ }^{\circ} \mathrm{Bx}$ allows beer analysis from a minimum sample volume. During fermentation of a sugar substrate with a constant original extract, the apparent extract is a linear function of the sample refraction.
\end{abstract}

Keywords: Balling, alcohol factors, attenuation quotient, interpolation, Balling formula, RDF, ADF, refraction

\section{Introduction}

World brewing uses a large Balling formula indicating the relationship between the original extract, alcohol and the actual beer extract. Carl Napoleon Balling (1805-1868) was a university professor in Prague and a prominent chemist in the field of metallurgy, sugar industry and fermentation chemistry (Basařová, 2005). He compiled his work in the mid-nineteenth century and published it in books from 1843 to 1865 , usually in three editions. Its essence is the design of so-called alcohol factors.

At that time, a patented instrument for analyzing wine and other alcoholic beverages according to Emil Tabarie was already known from 1830, based on the alcohol to be dissipated from wine in the air. Both procedures utilized an immersed saccharometer, calibrated with a cane or beet sucrose solution.

Balling knew this procedure but chose a classical beer analysis, using the relationship between the relative density of the alcohol obtained by distillation and the relative density of the extract solutions remaining in the evaporator residue after distillation, refilled with water to the original beer weight. As a control, he also vaporized the beer sample to dryness and, after refilling it to its original weight by water, found the amount of real extract. Winemakers later also verified this procedure, but did not recommend it for wine analysis.

Isolated alcohol factor values are usually reported in early-century works (Hrach, 1927; Pawlovski and Doemens, 1932). Both works are probably based on the same source in Germany in the early 19th century:

... Alcoholic factors are relative, dimensionless numbers that indicate the relationship between the original density of wort, the apparent and real attenuation of beer, and the amount of alcohol contained in it. Balling experimentally determined these numbers for worts of 1-30\% (Hrach, 1927).

Therefore, most brewers also believe that Balling determined the values of the so-called alcohol factors based on the results of fermentation tests.

Since the Balling theory was published, the relationship between the alcohol content and the density of the original wort has been modified in different ways depending on the fermentation industry. Most of the comments to date on the validity of the Balling formula are summarized in a review by Scandinavian authors, called 
"Balling's formula - careful scrutiny of brewing dogma" (Nielsen and Christiansen, 2007).

With the invention of direct measurement of the sample density in the oscillating U-tube and the alcohol content by infrared spectrophotometry by PAAR (Austria), the computational relations were further complicated. These changes depended on the practices of individual fields of sugar, beer, wine or spirits production. In brewing, the EBC Commission recommended the International Organization of the International Metrology Legale (OIML), (Rosendal and Schmidt, 1987). The same material also states the replacement of tables by polynomial development for alcohol, the apparent and real extract.

In addition, the results of the analyses had to be supplemented by converting the absolute density of the samples to the concentrations of their important components. The modified Tabarie procedure was well suited to this, but the confusion was caused by the observed interactions between alcohol and sucrose in a model solution (Hackbarth, 2009; Hackbarth, 2011).

The observed difference was reflected in the calculation of the degree of fermentation especially in the articles of American authors (Cutaia and Munroe, 1979). The relationship of Balling's alcohol factors to contemporary brewing has been addressed in our previous reports (Košin et al., 2013; Šavel et al., 2015).

The importance of these factors increases with the development of microbreweries, as they allow easy calculation of the alcohol content, knowing the original fermented batch extract and the apparent extract measured during fermentation.

Attainable fermentation values, referred to as the real degree of fermentation (RDF) or apparent degree of fermentation (ADF), were used to select malt for beer production. ADF values also depend on alcohol content and therefore RDF is a more appropriate parameter (Huerta-Zurita et al., 2019). The aim of our article is to compare two ways of calculation.

\section{Results and discussion}

\subsection{Interpolation formulas for calculation of alcohol factors}

Alcohol factors and their definitions were taken from the work of Hrach (1927). Since this work gives only isolated values depending on the original extract from 1 to $30 \%$ $(\mathrm{m} / \mathrm{m})$ in steps of $1 \%$, we present continuous interpolation formulas for this whole range.

Balling's original balance was based on the classical equation of Lavoisier and Gay Lussac:

$$
\mathrm{C}_{6} \mathrm{H}_{12} \mathrm{O}_{6}=2 \mathrm{C}_{2} \mathrm{H}_{5} \mathrm{OH}+2 \mathrm{CO}_{2}
$$

The balance of this equation was described by Balling as:

$$
\mathrm{Z}=\mathrm{A}+\mathrm{K}
$$

where Z (Zucker) is sugar (glucose), A alcohol and K (Kohlensaure) is carbon dioxide. Using the molecular weights, rounded to the nearest integer, the reciprocal of the basic alcohol yield coefficient for glucose fermentation can be calculated:

$$
\frac{M_{\text {glu }}}{2 M_{\text {EtoH }}}=\frac{180}{92}=1.9565
$$

which coincides with the commonly reported coefficient for the amount of glucose, calculated per $1 \mathrm{~g}$ of ethanol. Sucrose was used to calibrate submerged saccharometers in sugar industry and concentration units referred to as ${ }^{\circ} \mathrm{Bx}$ (Brix); in brewing Balling introduced his own degrees $\left({ }^{\circ} \mathrm{Bg}\right)$, which later converted to commonly used units called Plato $\left({ }^{\circ} \mathrm{P}\right)$.

1 degree Brix is $1 \mathrm{~g}$ sucrose in $100 \mathrm{~g}$ solution $(1 \% \mathrm{~m} / \mathrm{m})$. Relative density (specific gravity) SG $\left(20^{\circ} \mathrm{C} / 20^{\circ} \mathrm{C}\right)=1.040$, i.e. it corresponds to $9.99325^{\circ} \mathrm{Bx}$ or $9.99359^{\circ} \mathrm{P}$. Small differences between the two scales can be neglected in brewing.

At that time, a discussion over the nature of fermentation between chemical and biological experts such as Liebig and Pasteur, was still pending. Yeast might initially be considered a classic catalyst whose weight did not change during the reaction, but Balling, as a chemical technologist, knew that the growth of yeast during fermentation contradicted it. Therefore, he later supplemented this balance with an increase of yeast dry matter as another component of the balance equation on the right side of Lavoisier and Gay-Lussac equation.

The resulting balance of the components on which the large Balling formula is based is therefore:

$100 \mathrm{~g}$ of extract $=48.391 \mathrm{~g}$ of alcohol $+46.286 \mathrm{~g} \mathrm{of} \mathrm{CO}_{2}$ $+5.323 \mathrm{~g}$ of dry matter of yeast

or, after conversion to $1 \mathrm{~g}$ of alcohol:

\subsection{5 g extract $=1.0000 \mathrm{~g}$ alcohol $+0.9565 \mathrm{~g} \mathrm{CO}_{2}+$ 0.11 g yeast dry matter}

This relationship can therefore be understood as a balance of the individual components of the equation, whereby carbon dioxide escapes during fermentation and the increase in yeast dry matter is removed by filtration. The large Balling formula can therefore be considered as a cor- 
rection of the basic fermentation balance by the removal of carbon dioxide and the grown dry matter of yeast:

$$
p\left(\frac{180+1.0665 A}{100}\right)=2.0665 A+n
$$

where the left side of the equation is increased by the fermented amount of carbon dioxide and yeast loss and its right side is equivalent to the amount of the original extract consumed by fermentation.

Balling's alcohol factors reported on relationships between quantities describing the composition of beer:

$$
A=(p-m) a=(p-n) b=(n-m) c
$$

where $a, b, c$ are alcohol factors,

$p$ is the concentration of the original wort,

$n$ is the actual extract and

$m$ is the apparent extract in mass percent.

The apparent extract $m$ was considered to be a virtual extract corresponding to the Balling saccharometer reading in beer. The attenuation quocient $q$ expresses the ratio between two alcoholic factors $(q=b / a)$.

Both Tabarie and Balling used a saccharometer to calculate the alcohol content of the fermented beverage, which, when immersed in a sucrose solution, indicated its concentration (Balling, 1854; Hebert, 1882). After sucrose fermentation, the Balling saccharometer reading was close to zero but rarely reached this value after beer fermentation. Balling called the saccharometer reading in the fermented beverage the apparent extract value $m$.

The Balling saccharometer showed zero in pure water or in a mixture of sucrose and alcohol in which the sum of the relative density of the sucrose solution $\mathrm{SG}_{\mathrm{sac}}$ $>1)$ and the alcohol $\left(\mathrm{SG}_{\mathrm{alc}}<1\right)$ equals 0 even though the densities of both solutions were non-zero. The relative density (SG) is the ratio of the absolute density of the component solution to the density of water at a defined temperature. The zero value of the apparent extract in this case is usually referred to as $m_{0}(\mathrm{~m} / \mathrm{m} \%)$.

For practical reasons, it was necessary to express the relationship between the actual and the apparent extract using the attenuation quotient $q$ continuously, and not only for isolated points from the published tables.

The values of interpolation formulas for classical Balling factors were obtained from the linear dependence of the quotient $q$, as shown in Table 1.

$$
q=1.220+0.001 p
$$

$$
q-1=0.220+0.001 p
$$

$$
b=\frac{1}{2.0665-0.010665 p}
$$

$$
a=\frac{b}{q}
$$

$$
c=\frac{b}{q-1}
$$

From the definition of the quotient $q$ it is possible to derive the relation for the calculation of the apparent extract $\left(m_{0}=0\right)$, in which the Balling saccharometer immersed in fermented sucrose or beer shows $0 \%$ by mass, similar to the immersion in pure water (for $n=0$ ).

$$
m_{0}=p\left(\frac{q-1}{q}\right)=p\left(1-\frac{1}{q}\right)
$$

where $m_{0}$ is zero value of the apparent beer extract, $p$ is the original beer extract.

However, the zero value $q$ at the origin of the coordinates $(p=0, m=0)$ must be excluded.

The interpolation of the dependence (9) gives an almost linear dependence of $m_{0}$ on the original extract (Figure 1).

The figure points indicate the concentration of sucrose or extract in fermented solutions on the scale of saccharometer submerged in a fermented sucrose solution, e.g. the original extract $p=10 \%$ responds to the actual extract $n_{0}=1.87 \%$ corresponding to the apparent extract value $m_{0}=0 \%$.

The figure shows positive zero values $\left(n_{0^{\prime}} m_{0}\right)$ in a fermented beverage in the mixture of a non-zero content of extract and alcohol depending on the original extract. The relationship between the apparent and the actual extract is determined by the quotient $q$, which increases the original extract linearly with each percent by one thousandth of $\% \mathrm{~m} / \mathrm{m}$. Non-zero initial value of 0.220 means that reducing the density of the solution due to alcohol is not sufficient to compensate for its effect due to the extract. 
Figure 1 Zero values of apparent extract $\left(\mathrm{m}_{0}\right)$ and corresponding real extract value $\left(\mathrm{n}_{\mathrm{e}}\right)$ versus original extract (p) of fermented beverage

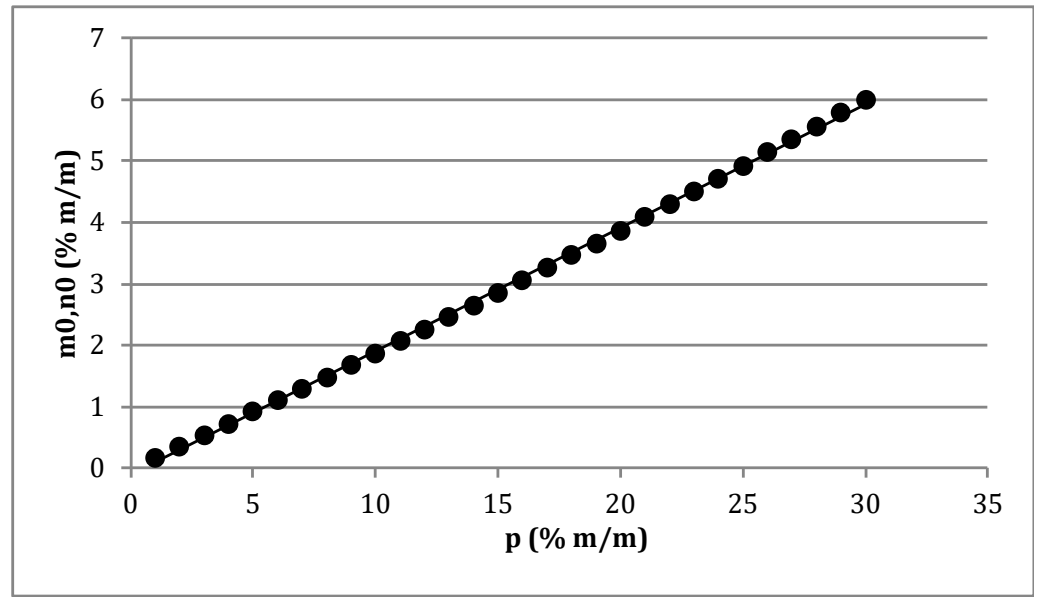

Table 1 Values of original (Hrach, 1927) and calculated alcohol factors using interpolation formula (number in brackets)

\begin{tabular}{|c|c|c|c|c|c|c|c|c|}
\hline & Hrach (1927) & Formula (4) & Hrach (1927) & Formula (7) & Hrach (1927) & Formula (6) & Hrach (1927) & Formula (8) \\
\hline $\mathrm{p}$ & $q$ & $q$ & a & a & b & b & c & c \\
\hline 1 & 1.221 & 1.221 & 0.3983 & 0.3984 & 0.4864 & 0.4864 & 2.2010 & 2.2009 \\
\hline 2 & 1.222 & 1.222 & 0.4001 & 0.4001 & 0.4889 & 0.4890 & 2.2024 & 2.2023 \\
\hline 3 & 1.223 & 1.223 & 0.4018 & 0.4019 & 0.4915 & 0.4915 & 2.2041 & 2.2040 \\
\hline 4 & 1.224 & 1.224 & 0.4036 & 0.4037 & 0.4941 & 0.4941 & 2.2058 & 2.2058 \\
\hline 5 & 1.225 & 1.225 & 0.4054 & 0.4055 & 0.4967 & 0.4967 & 2.2076 & 2.2076 \\
\hline 6 & 1.226 & 1.226 & 0.4073 & 0.4073 & 0.4993 & 0.4994 & 2.2096 & 2.2093 \\
\hline 7 & 1.227 & 1.227 & 0.4091 & 0.4091 & 0.5020 & 0.5020 & 2.2116 & 2.2115 \\
\hline 8 & 1.228 & 1.228 & 0.4110 & 0.4110 & 0.5047 & 0.5047 & 2.2137 & 2.2136 \\
\hline 9 & 1.229 & 1.229 & 0.4129 & 0.4129 & 0.5074 & 0.5075 & 2.2160 & 2.2157 \\
\hline 10 & 1.230 & 1.230 & 0.4148 & 0.4148 & 0.5102 & 0.5102 & 2.2181 & 2.2183 \\
\hline 11 & 1.231 & 1.231 & 0.4167 & 0.4167 & 0.5130 & 0.5130 & 2.2209 & 2.2208 \\
\hline 12 & 1.232 & 1.232 & 0.4187 & 0.4187 & 0.5158 & 0.5159 & 2.2234 & 2.2233 \\
\hline 13 & 1.233 & 1.233 & 0.4206 & 0.4208 & 0.5189 & 0.5187 & 2.2262 & 2.2270 \\
\hline 14 & 1.234 & 1.234 & 0.4226 & 0.4226 & 0.5215 & 0.5216 & 2,2290 & 2,2286 \\
\hline 15 & 1.235 & 1.235 & 0.4246 & 0.4247 & 0.5245 & 0.5245 & 2.2319 & 2.2319 \\
\hline 16 & 1.236 & 1.236 & 0.4267 & 0.4267 & 0.5274 & 0.5275 & 2.2350 & 2.2247 \\
\hline 17 & 1.237 & 1.237 & 0.4288 & 0.4288 & 0.5304 & 0.5304 & 2.2381 & 2.2380 \\
\hline 18 & 1.238 & 1.238 & 0.4309 & 0.4309 & 0.5334 & 0.5335 & 2.2414 & 2.2412 \\
\hline 19 & 1.239 & 1.239 & 0.4330 & 0.4330 & 0.5365 & 0.5365 & 2.2448 & 2.2448 \\
\hline 20 & 1.240 & 1.240 & 0.4351 & 0.4352 & 0.5396 & 0.5396 & 2.2483 & 2.2483 \\
\hline 21 & 1.241 & 1.241 & 0.4373 & 0.4373 & 0.5427 & 0.5427 & 2.2519 & 2.2519 \\
\hline 22 & 1.242 & 1.242 & 0.4395 & 0.4395 & 0.5427 & 0.5427 & 2.2557 & 2.2554 \\
\hline 23 & 1.243 & 1.243 & 0.4417 & 0.4417 & 0.5458 & 0.5459 & 2.2595 & 2.2593 \\
\hline 24 & 1.244 & 1.244 & 0.4439 & 0.4439 & 0.5522 & 0.5523 & 2.2636 & 2.2631 \\
\hline 25 & 1.245 & 1.245 & 0.4462 & 0.4462 & 0.5555 & 0.5556 & 2.2677 & 2.2673 \\
\hline 26 & 1.246 & 1.246 & 0.4495 & 0.4486 & 0.5589 & 0.5589 & 2.2719 & 2.2720 \\
\hline 27 & 1.247 & 1.247 & 0.4508 & 0.4508 & 0.5622 & 0.5623 & 2.2763 & 2.2761 \\
\hline 28 & 1.248 & 1.248 & 0.4532 & 0.4532 & 0.5656 & 0.5656 & 2.2808 & 2.2806 \\
\hline 29 & 1.249 & 1.249 & 0.4556 & 0.4556 & 0.5690 & 0.5691 & 2.2854 & 2.2851 \\
\hline 30 & 1.250 & 1.250 & 0.4580 & 0.4580 & 0.5725 & 0.5726 & 2.2902 & 2.2900 \\
\hline
\end{tabular}




\subsection{Calculation of the degree of fermentation}

Balling defined the degree of fermentation for both the apparent and the actual extract, later reported as a percentage:

$$
V_{m, v}=100 \frac{p-m, n}{p}
$$

where $\mathrm{V}$ is the degree of fermentation (Vergärungsgrad).

Analytica ASBC proposes two formulas for actual real degree of fermentation (RDF), based on its earlier adjustments, while the apparent degree of fermentation (ADF) has not changed (Analytica ASBC, 1992).

$$
R D F=\left[100\left(\frac{p-n}{p}\right)\right]\left[\frac{1}{(1-0.005161) n}\right]
$$

Both formulas are based on the correction of partially removed components during fermentation of wort to beer. Formula (12) therefore describes fermentation without volatile components leakage, since the relationship numerator is the amount of sucrose consumed by fermentation and the denominator is its amount without removing both volatile and non-volatile components at its end. This type of fermentation could be realized, for example, by fermentation in an isolated system and monitoring its progress by measuring the increase in carbon dioxide pressure.

In the brewing industry, it has long been preferred to measure the apparent extract over the actual one for its simplicity. The brewers followed the fermentation process by immersing the saccharometer into a shaken or even unshaken sample. With the establishment of laboratories, at least in larger breweries, the real extract was considered as a supplementary figure obtained by calculation.

EBC analysts differentiated between wort analysis prepared by classical congressional mashing or hot water mashing and resulting in terms of fermentability and ap- parent fermentation that were converted to true fermentation by multiplying by a constant factor. The fermentability calculation was also based on a procedure in which the SG value was reduced by 1 and multiplied by 1000 according to the practices of smaller breweries in England.

The selection of suitable barley varieties for the production of Czech beer was also based on the measurement of the apparent extract. The calculation of achievable fermentation is also closely related to the economy of the fermenting industry, which now dominates the industry as traditional as brewing.

In a different way, the US brewing industry has made corrections to the fermented wort components that are removed prior to analysis. Later, the effect of sucrose-ethanol interactions in fermentation products was demonstrated, leading to newly designed formulas for calculating their analyses while maintaining the previous correction.

The same trend was seen in beer analysis, where Balling distillation was maintained for a long time in which the correction for beer residues in yeast and leaked carbon dioxide did not apply but, on the contrary, ensured the equivalence of calculation of the original extract from alcohol factors (Analytica EBC, 2004).

Moreover, in 1997 it was possible to calculate RDF according to EBC method 9.5, which responds to formula (12), or to ASBC method responding to formula (11) (Analytica ASBC, 1992).

The differences between the calculation of the real degree of fermentation (RDF) according to EBC or ASBC may vary by 1 to $2 \%$ for current beers (Table 2 ). RDF was calculated according to (10) for $\mathrm{V} n=60 \%$ with the help of (11), (12). Real extract was, e.g. $n=p(1-0,6)$ for chosen parameter $p$. The resulting alcohol A was calculated from classical Balling formula.

Alcohol factor values are also dependent on original extract and are therefore of historical significance, as they actually indicate the composition of beers from the early of 19 th century, regardless of the degree of fermentation used before the onset of HGB (high gravity brewing).

Large breweries mostly take pride in the traditional method of production, which has changed only slightly with the introduction of modern technologies.

Table 2 Examples of RDF values calculated by Balling (RDF $=60 \%)$ and interpolation formulas (11) and (12)

\begin{tabular}{|c|c|c|c|c|c|}
\hline $\mathrm{p}(\% \mathrm{~m} / \mathrm{m})$ & $\mathrm{n}(\% \mathrm{~m} / \mathrm{m})$ & $\mathrm{A}(\% \mathrm{~m} / \mathrm{m})$ & Balling (1854) & Formula (11) & Formula (12) \\
\hline 1 & 0.40 & 0.29 & 60.0 & 60.1 & 60.1 \\
\hline 5 & 2.00 & 1.49 & 60.0 & 60.6 & 60.6 \\
\hline 10 & 4.00 & 3.06 & 60.0 & 61.3 & 61.3 \\
\hline 20 & 8.00 & 6.48 & 60.0 & 62.6 & 62.6 \\
\hline 30 & 12.00 & 10.31 & 60.0 & 64.9 & 64.9 \\
\hline
\end{tabular}


Figure 1 gives the zero value of apparent extract value $m_{0}$ selected for the original extract, for which saccharometer with a scale starting at zero value can be used.

The Tabarie and Balling analysis procedure utilized the determination of residual beer extract by evaporating the sample and bringing it back to its original volume or weight, necessary for saccharometer immersion or filling the pycnometer. Thus, with some exaggeration, both methods can be considered as a kind of weighing analysis by evaporation of a beverage sample. The disadvantage of the immersion saccharometer was its large size, which made it impossible to use it in beer analysis. The use of a refractometer made it possible to reduce the sample volume. It would therefore be interesting to observe the possible fate of beer analysis based on refractometry, whereby extracts such as sucrose and ethanol were measured in a linear region with a refractometer set to Brix degrees. Linear relationships existed between sucrose (0 to $16 \%$ $\mathrm{m} / \mathrm{m}$ ) and alcohol (0 to $8 \% \mathrm{~m} / \mathrm{m}$ ) and refraction of the original beer sample (Košin and Šavel, 2013).

A pocket digital refractometer with automatic temperature correction is currently available for purchase. Thus, it is possible to determine the alcohol and the extract from a few $\mathrm{ml}$ of beer and knowing the original extract from an even smaller amount of beer. During fermentation of a sugar substrate with a constant original extract, the apparent extract is a linear function of the sample refraction set to ${ }^{\circ} \mathrm{Bx}$.

\section{Conclusion}

The article deals with the interpolation of the Balling alcohol factors given at isolated points in $1 \%(\mathrm{~m} / \mathrm{m})$ increments ranging from 1 to $30 \%$ in the Hrach table published in 1927. The interpolation was necessery for the calculation of the real (RDF) or the apparent (ADF) degree of attenuation in a continuous range of original extract. A comparison was made between the two ways of RDF calculation according to EBC and ASBC The results can help develop simple control methods for home and craft breweries.

\section{List of symbols}

$\begin{array}{ll}\mathrm{p} & \text { original extract }(\% \mathrm{~m} / \mathrm{m}) \\ \mathrm{A} & \text { alcohol }(\% \mathrm{~m} / \mathrm{m}) \\ \mathrm{n} & \text { real extract }(\% \mathrm{~m} / \mathrm{m}) \\ \mathrm{m} & \text { apparent extract }(\% \mathrm{~m} / \mathrm{m}) \\ \mathrm{m}_{0^{\prime}} \mathrm{n}_{0} & \text { zero reading of saccharometer }(\% \mathrm{~m} / \mathrm{m}) \\ \mathrm{RDF} & \text { real degree of fermentation }(\%)\end{array}$

$\begin{array}{ll}\text { ADF } & \text { apparent degree of fermentation (\%) } \\ \mathrm{SG} & \text { specific density } \\ \mathrm{SG}_{\mathrm{alc}} & \text { specific density of alcohol solution } \\ \mathrm{SG}_{\mathrm{sac}} & \text { specific density of sucrose solution } \\ \mathrm{V}_{\mathrm{m}, \mathrm{n}} & \text { Balling degree of fermentation (\%) } \\ \mathrm{a}, \mathrm{b}, \mathrm{c} & \text { alcohol factors } \\ \mathrm{q} & \text { attenuation quotient }\end{array}$

\section{References}

Analytica ASBC, 1992: Method Beer-6 Real degree of fermentation. Methods of analysis ASBC 8. Revised edition. St. Paul, Minnesota, USA, 1992. ISBN 1-881696-01-04.

Analytica EBC, 2004: Method 9.4 Original, real and aparent extract and original gravity of beer - Carl-Hans Verlag. Nürnberg.

Analytica EBC, 1997: Method 9.5 Real degree of fermentation - Carl-Hans Verlag. Nürnberg.

Balling, C.J.N., 1854: Die Gärungschemie wissenschaftlich begründet und in ihrer Anwendung auf die Bierbrauerei, Branntweinbrennerei, Hefeerzeugung, Weinbereitung und Essigfabrikation praktisch dargestellt. Bierbreauerei wissenschaftchlich begründet und praktisch dargestellt. 2. vyd. Verlag von Friedrich Tempský, Prag, 1854.

Barnett, J.A. (2003): Beginning of microbiology and biochemistry: the contribution of yeast research. Microbiology, 149(3), 557-567. https://doi.org/10.1099/mic.0.26089-0

Basařová, G. (2005): Profesor pražské techniky Carl Joseph Napoleon Balling. Kvasny prumysl, 51(4), 130-135. https://doi.org/10.18832/ kp2005007

Cutaia, A.J., Munroe, J.H. (1979): A method for the consistent estimation of real degree of fermentation. J. Am. Soc. Brew. Chem., 37(4), 188-189. https://doi.org/10.1094/ASBCJ-37-0188

Cutaia, A.J., Reid, A., Speers, R.A. (2009): Examination of the relationships between original, real and apparent extracts, and alcohol in pilot plant and commercially produced beers. J. Inst. Brew., 115(4), 318-327. https:// doi-org.ezproxy.techlib.cz/10.1002/j.2050-0416.2009.tb00387.x

Hackbarth, J. J. (2009): The effect of ethanol-sucrose interactions on specific gravity:: A new algorithm for estimating specific gravity. J. Am. Soc. Brew. Chem., 67(3), 146-151. https://doi-org.ezproxy.techlib. cz/10.1094/ASBCJ-2010-1207-01

Hackbarth, J. J. (2011): The effect of ethanol-sucrose interactions on specific gravity. Part 2: A New Algorithm for Estimating Specific Gravity. J. Am. Soc. Brew. Chem., 69(1), 39-43. https://doi-org.ezproxy.techlib.cz/10.1094/ASBCJ-2010-1207-01

Hebert, L.: The register of arts, and Journal of patent inventions. Vol. sixth, new series. London, ed. Steil, B., Paternoster row, 1882.

Hrach, J. F. (1927): Alkoholové faktory. Technický slovník naučný, ilustrovaná encyklopedie věd technických (15 dílů), díl 1., s. 343., Vyd. Borský a Šulc. Praha XI, 1927.

Huerta-Zurita, R., Horsley, R.D., Schwarz, P.B. (2019): Is the apparent degree of fermentation a reliable estimator of fermentability? J. Am. Soc. Brew. Chem., 77(1), 1-9. https://doi-org.ezproxy.techlib.cz/10. 1080/03610470.2018.1553459

Košin, P., Šavel, J., Brož, A. (2013) Výpočet extraktů míchaného nápoje z piva. Kvasny prumysl, 59(9), 258-261. https://doi.org/10.18832/ kp2013026

Nielsen, H., Kristiansen, A. G., Lasen, K.M., Erikstrøm, C. (2007): Balling's formula - scrutiny of a brewing dogma. Brauwelt Int., II, 90-93.

Pawlowski, R., Doemens, A., 1932, Die Brautechnischen Untersuchungsmethoden. Verlag von R. Oldenburg, München, 1932. 
Rosendal, I., Schmidt, F. (1987): European Brewery Convention. The alcohol table for beer analysis and polynomials for alcohol and extract. J. Inst. Brew., 93(5), 373-377. https://doi. org/10.1002/j.2050-0416.1987.tb04519.x
Šavel, J., Košin, P., Brož., A. (2015): Ballingovy alkoholové faktory z pohledu současného pivovarství. Kvasny prumysl, 61(4), 120-128. https://doi.org/10.18832/kp2015015 